\title{
Evaluation of heterogeneity of DNA ploidy in early gastric cancers
}

\author{
M.C. Osterheld *, R. Laurini, E. Saraga and \\ F.T. Bosman \\ University Institute of Pathology of Lausanne, \\ Switzerland
}

Received 12 May 1999

Accepted 20 August 1999

DNA ploidy has been shown to be a predictive parameter for prognosis in various solid tumours. The prognostic value of DNA-ploidy in gastric cancers is still a matter of controversy. A possible explanation for the discrepant results reported in the literature could be sampling error in tumours with multiple stemlines differing in DNA-ploidy.

In order to determine whether or not such heterogeneity exists in early gastric carcinoma, we have performed DNA cytophotometry on multiple samples of a group of 17 early gastric carcinomas, of which 8 were pure intramucosal and 9 were infiltrating into the submucosa.

We found an aneuploid DNA-stemline in 8 (47\%) early gastric cancers, more often in tumours invading into the submucosa (5/9) than in purely mucosal tumours (3/8). Multiple DNA-stemlines were found more frequently in submucosally infiltrating tumours (4/5).

These results confirm the presence of DNA-aneuploid early gastric carcinoma which are frequently heterogeneous and suggest that heterogeneity occurs more frequently in tumours invading the submucosa. This heterogeneity is best detected by analysing multiple samples of tumours for DNAploidy.

\section{Introduction}

Several studies have reported a correlation between DNA-ploidy and prognosis in gastric carcinomas [1,7$9,20,21,28]$. Other studies have indicated that there is no correlation between prognosis and DNA-ploidy [3].

\footnotetext{
*For correspondence: M.C. Osterheld, MD, University Institute of Pathology, Rue du Bugnon 25, 1011 Lausanne, Switzerland. Tel.: +41 21314 7111; Fax: +41 2131471 15; E-mail: MariaChiara.Osterheld@chuv.hospvd.ch.
}

As explanation for this discrepancy several possibilities come into consideration. These studies differ in methodology (static vs. flow cytometry; tissue preparation), in their definition of DNA-aneuploidy, in the number of patients studied. All these variables might affect the final result.

Tumour heterogeneity, the presence within the same tumour of multiple stemlines differing in DNA content, has been described in various tumours $[10,14,16$, $18,24,28]$. The occurrence of such cellular heterogeneity in gastric carcinomas might yet be another explanation of the divergent DNA-ploidy results in this type of tumour.

In a previous study on DNA-ploidy in early gastric carcinomas with focal advanced gastric carcinoma [15] we observed that most tumours were diploid. This seems not to be in keeping with the possibility of heterogeneity. The number of samples studied per tumour, however, might have been too small to exclude this possibility.

For the present study, our working hypothesis was that although the majority of early gastric carcinomas (EGC) are genetically (in terms of DNA-ploidy) homogeneous, some cases might show heterogeneity [22]. Heterogeneity, indicating the emergence of variant DNA-stemlines, indicates tumour progression and might therefore be preferentially found in larger lesions that invade deeper than the mucosa. To test this hypothesis, we extensively sampled 17 cases of EGC in search for multiple DNA-stemlines. We compared the DNA-ploidy results with clinicopathological variables, including patient survival, tumour size and depth of invasion.

\section{Material and methods}

Seventeen cases of EGC diagnosed in gastrectomy specimens obtained between 1976 and 1992 were used for this study. These cases included eight intramucosal carcinomas and nine tumours also invading the submucosa. Only those cases were included for which mul- 

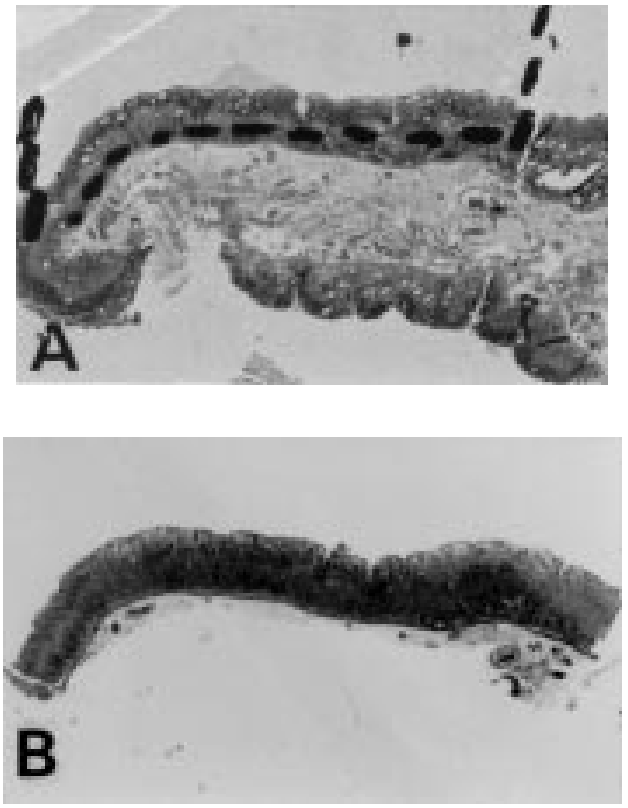

Fig. 1. (A) Shows a section from an EGC before microdissection. Note doted line limiting the area to be dissected $(\mathrm{HE}, \times 2.4)$. (B) Illustrates the dissected sample used for ploidy assessment (HE, $\times 2.4)$

tiple histological samples were available. All available gross and histological material was reviewed and clinical data were obtained from pathology reports and from referring clinicians.

In all gastrectomy specimens, the tumour was mapped in detail following the protocol of Mori [12], which allowed detailed histological analysis of the tumours and measurement of the size of the intramucosal and of the submucosal components. The number of samples for cytophotometric DNA analysis in each case was calculated as a function of the maximal diameter of the tumour (one sample per two centimetres/maximal length). In addition one sample of normal gastric mucosa was examined for each case. Hematoxylin and eosin stained slides were screened to identify the intramucosal and the submucosal components. In addition, the tumors were classified according to their histological type following the WHO classification [11].

For selective evaluation of DNA ploidy the intramucosal and the infiltrative components were separately sampled on the corresponding paraffin blocks, by means of a dissecting microscope. Moreover, we carried out a histological control of the blocks following dissection (Fig. 1).

Seventy-six blocks were processed for DNA assessment, with an average number of 4.5 blocks per case, including samples from normal gastric mucosa.
All dissected blocks were processed following the technique of Hedley [5]. Feulgen staining was done as following: the slides were first hydrolysed in $5 \mathrm{~N}$ hydrochloric acid at $25^{\circ} \mathrm{C}$ for 45 minutes. The hydrolysis was stopped by rinsing in distilled water. They were then stained with Schiff's reagent (Schiff's reagent for microscopy, No 1.0933, Merck) for 60 minutes. Sulfite rinse was used to remove surplus dye. They were rinsed and dehydrated in subsequently changes of alcohol 50\%, 70\%, ethanol alcohol and xylene for 3 minutes each before being coverslipped using Eukitt mounting medium. DNA analysis was performed on Feulgen-stained cytospins using an image analysis system (SAMBA, Alcatel TITN Answare, Grenoble, France). A minimum of 150 nuclei was measured per smear (300 nuclei for most cases). Only well preserved nuclei were selected by the operator using the gallery program of SAMBA system (SAMBA, Alcatel TITN Answare, Grenoble, France). As a control we used 30 to 50 human lymphocytes (external reference) with a coefficient of variation of $5 \%$ (average) and $6.5 \%$ (maximal), and at least 6 tissue polymorphonuclear leukocytes (internal reference) when available. Histograms exhibiting a G0/1 main peak at $2 \mathrm{C}$ were considered to be diploid (index 0.85-1.15). Considering that in normal tissues and most low-grade or slowly proliferating neoplasms, approximately $85 \%$ of the cell population form the G0/1 peak and $15 \%$ of the cells in the S-phase and G2/M phases [2,19], we have only considered as aneuploid the samples with more than $15 \%$ of cells with a DNA-index in excess of 1.15 . A sample was considered tetraploid when a peak was found between DNA indices of 1.70 and 2.30 comprising at least $15 \%$ of the cells. Similarly, a triploid sample was defined by a DNA-index between 1.3 and 1.75. All the events $>1.15$ and not displaying a tetraploid or a triploid peak were considered hyperploid (cell population with an abnormal content of DNA considered aneuploid but not corresponding to a defined peak). The tumours analysed were divided into two groups, diploid and aneuploid, the latter regardless of the subtype of aneuploidy (hyperploid, triploid or tetraploid).

A tumour was regarded heterogeneous when at least one sample had a ploidy pattern different from the others (Fig. 2). A tumour was considered diploid when all samples were diploid (homogeneous). A tumour was considered aneuploid when at least one sample was aneuploid (heterogeneous) or all samples were aneuploid (homogeneous). Possible correlation between ploidy and depth of tumour invasion or heterogeneity were statistically analysed by means of the Fischer's exact test. A $P$ value of less than 0.05 was considered statistically significant. 

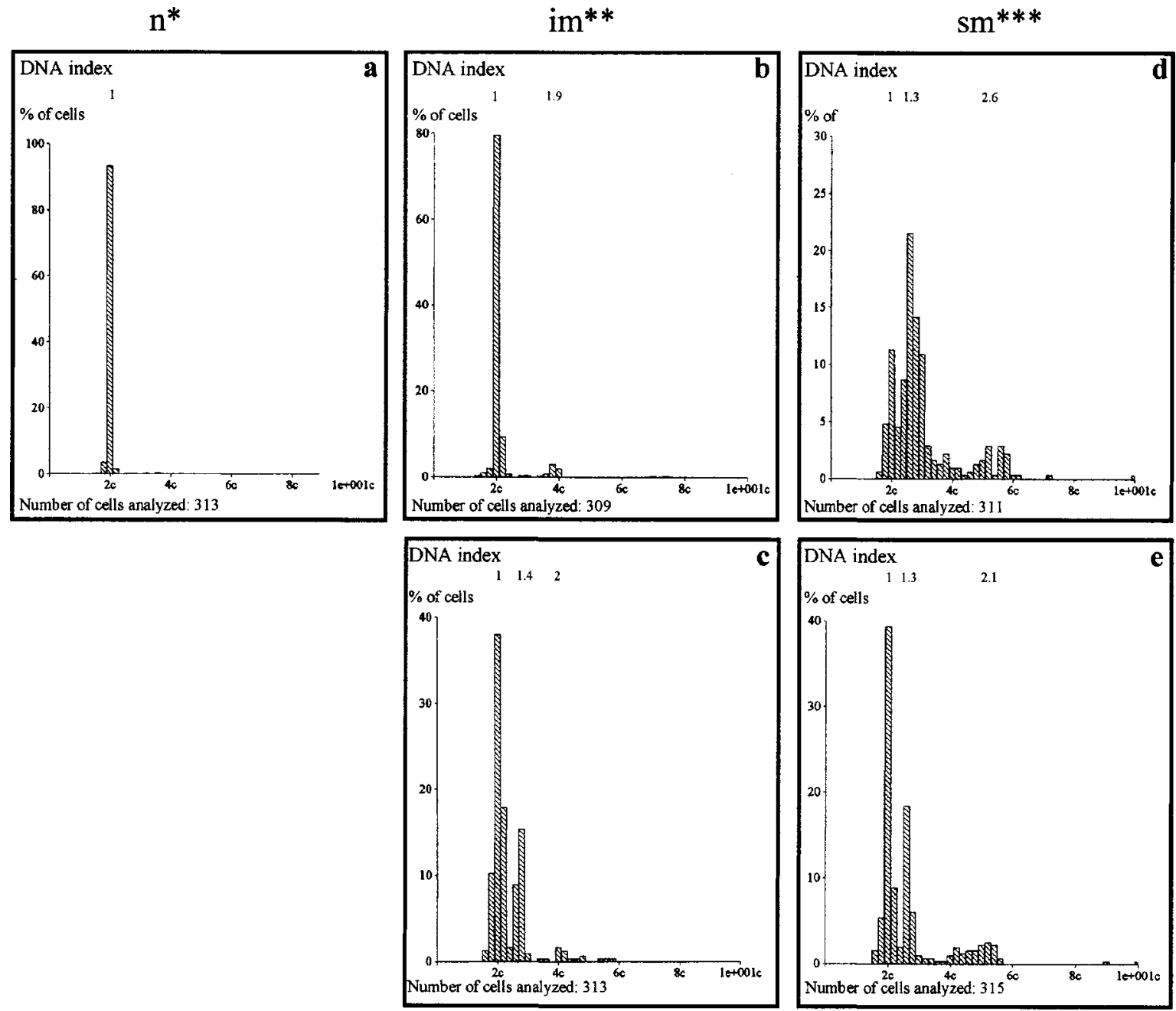

Fig. 2. Histograms illustrating intratumoral DNA-ploidy heterogeneity: *Normal mucosa diploid (a); **intramucosal component showing a diploid (b) and an aneuploid (c) histogram; ***submucosal component ((d) and (e)) showing a variable degree of aneuploidy.

\section{Results}

We studied 17 patients ( 7 women, 10 men). Average age at gastrectomy was 60 years. All tumours were located in the small curvature of the stomach, most commonly in the antrum at the level of the angulus. The macroscopic pattern was classified according to the system proposed by the Japanese Society of Gastroenterological Endoscopy [14] into type I (protruded type), type IIa (elevated type), b (flat type), c (depressed type) or type III (excavated type) and corresponded mainly to the types II and III. Follow-up data were available of 15 patients. Twelve (87\%) patients were still alive 10 years after gastrectomy. One patient presented liver metastases and died eight years after surgery, another died five years after surgery with lo- cal recurrence and lymph node metastases, and one patient died three years after surgery with multiple metastases.

Of our tumours $8(45 \%)$ were purely intramucosal and $9(55 \%)$ also contained areas of submucosal infiltration (Fig. 3). The size of the tumours varied between $7 \times 6$ and $3.5 \times 2.5 \mathrm{~cm}$. Tumours with submucosal invasion were not significantly larger than those without. The submucosal component comprised on the average $24 \%$ of the total size (range 3-71\%). The DNA analysis of all the normal gastric mucosa samples invariably showed a diploid pattern (100\%).

Of the 17 tumours, 9 (53\%) were diploid and 8 (47\%) aneuploid. Of the 8 intramucosal carcinomas, $5(63 \%)$ were diploid and $3(37 \%)$ aneuploid. Of the 9 submucosal tumours $5(55 \%)$ were aneuploid and 4 

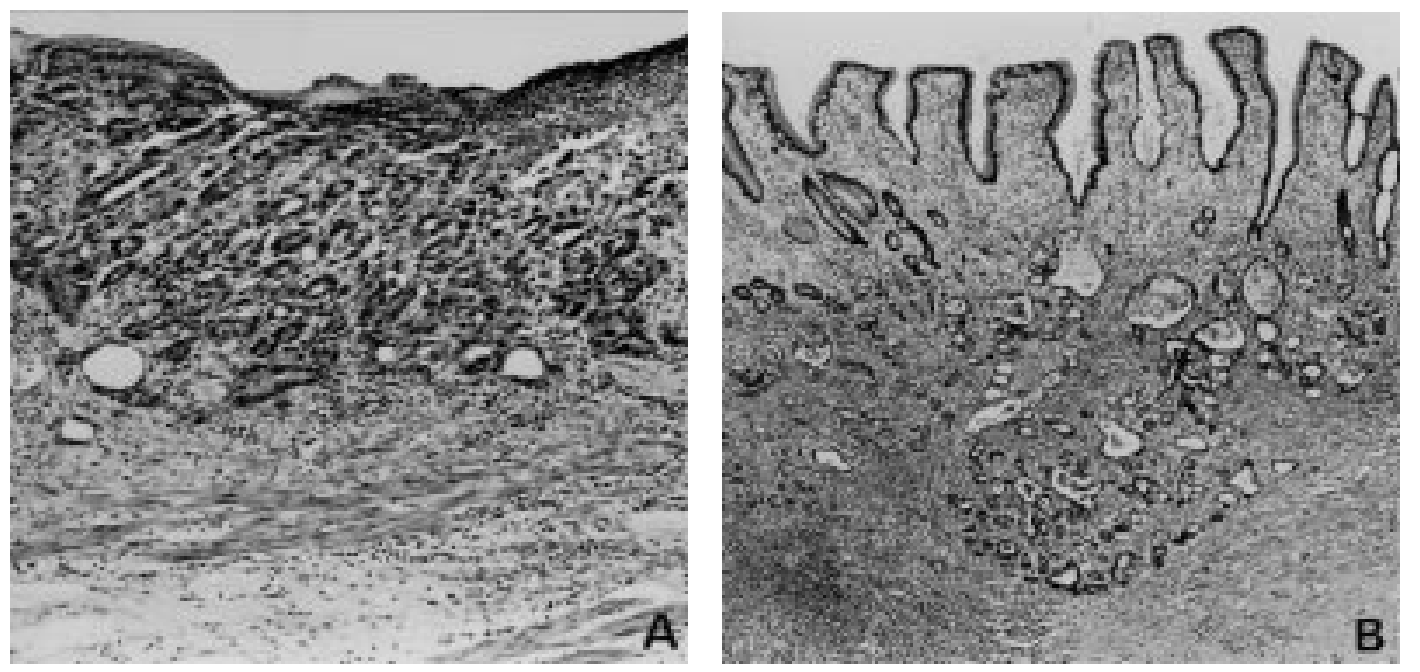

Fig. 3. View of a histological section cut through an area of intramucosal EGC (A) $(\mathrm{HE}, \times 150)$ and through an area of infiltrating submucosa $\mathrm{EGC}(\mathrm{B})(\mathrm{HE}, \times 80)$.

Table 1

DNA-ploidy pattern in pure intramucosal EGC

\begin{tabular}{ccccccccc}
\hline Cases & Age/sex & Origin & Size of EGC & \multicolumn{3}{c}{ Samples } & DNA-ploidy & Heterogeneity \\
\cline { 4 - 6 } & & & i.m $(\mathrm{cm} \times \mathrm{cm})$ & Total* & $\mathrm{D}$ & $\mathrm{A}$ & & \\
\hline 1 & $70 / \mathrm{M}$ & i.m & $4.5 \times 2.5$ & 3 & 3 & 0 & $\mathrm{D}$ & no \\
2 & $70 / \mathrm{F}$ & i.m & $5 \times 5$ & 3 & 3 & 0 & $\mathrm{D}$ & no \\
3 & $81 / \mathrm{F}$ & i.m & $4.5 \times 2$ & 3 & 0 & 3 & $\mathrm{~A}$ & no \\
4 & $17 / \mathrm{F}$ & i.m & $5.5 \times 4$ & 3 & 2 & 1 & $\mathrm{~A}$ & yes \\
5 & $44 / \mathrm{F}$ & i.m & $6 \times 4$ & 3 & 3 & 0 & $\mathrm{D}$ & no \\
6 & $42 / \mathrm{F}$ & i.m & $4 \times 3.5$ & 2 & 2 & 0 & $\mathrm{D}$ & no \\
7 & $75 / \mathrm{M}$ & i.m & $5.5 \times 1+0.5 \times 0.5$ & 3 & 0 & 3 & $\mathrm{~A}$ & no \\
8 & $57 / \mathrm{F}$ & i.m & $5.5 \times 3.5$ & 3 & 3 & 0 & D & no \\
\hline Total & 8 cases & & & 23 samples & 5 diploid & \\
& & & & & 3 aneuploid & 1 heterogeneous \\
\hline
\end{tabular}

D = DNA-diploid; A = DNA-aneuploid; i.m = intra-mucosal component; $*$ Total $=$ total number of samples analysed per case.

(45\%) diploid $(P=0.39)$. Heterogeneity was present in 5 cases, one in intramucosal $(1$ of $8 ; 13 \%)$ but 4 ( 4 of $9 ; 44 \%)$ in submucosally infiltrating cases $(P=0.18)$.

Neither aneuploidy or heterogeneity were related to the size of EGC (Tables 1 and 2). Furthermore, no significant correlation was found between the different histological types (WHO classification) and the incidence of aneuploidy or heterogeneity. All available lymph nodes were negative for metastases except for case 9 with $2 / 8$ metastatic lymph nodes.

\section{Discussion}

The malignant potential of different tumours has been correlated with DNA-ploidy, and it has been shown that the presence of aneuploid cell populations frequently is an indicator of poor prognosis. Several studies have been published on DNA-ploidy in gastric cancer; most indicate that DNA-aneuploidy is an indicator of unfavourable prognosis [1,7-9,20,21], but others failed to confirm this finding [3].

Tumour heterogeneity has been a consistent finding in DNA-ploidy analysis, e.g., of colorectal cancer [16, 27]. Sampling error of heterogeneous gastric tumours could explain, at least partly, the conflicting results for gastric cancer. DNA-ploidy studies in advanced gastric cancers have confirmed that heterogeneity exists. It appears to occur more frequently in deeply invading tumours, which suggests that advanced tumours might be more heterogeneous $[6,23]$. If ploidy heterogeneity is a 
Table 2

DNA-ploidy patterns in EGC infiltrating mucosa and submucosa

\begin{tabular}{|c|c|c|c|c|c|c|c|c|c|}
\hline \multirow[t]{2}{*}{ Cases } & \multirow[t]{2}{*}{ Age/sex } & \multirow[t]{2}{*}{ Origin } & \multicolumn{2}{|c|}{ Size of EGC } & \multicolumn{3}{|c|}{ Samples } & \multirow[t]{2}{*}{ DNA-ploidy } & \multirow[t]{2}{*}{ Heterogeneity } \\
\hline & & & i.m $(\mathrm{cm} \times \mathrm{cm})$ & $\mathrm{s} . \mathrm{m}(\mathrm{cm} \times \mathrm{cm})$ & Total* & $\mathrm{D}$ & $\mathrm{A}$ & & \\
\hline 1 & $66 / \mathrm{M}$ & i.m & $4 \times 2.5$ & & 2 & 2 & 0 & $\mathrm{~A}$ & yes \\
\hline \multirow[t]{2}{*}{2} & $62 / \mathrm{M}$ & i.m & $5 \times 4$ & & 3 & 3 & 0 & $\mathrm{D}$ & no \\
\hline & & s.m & & $1 \times 1$ & 1 & 1 & 0 & & \\
\hline 3 & & s.m & & $5 \times 2.5$ & 3 & 0 & 3 & & \\
\hline \multirow[t]{2}{*}{4} & $43 / \mathrm{F}$ & i.m & $4 \times 3.5$ & & 2 & 2 & 0 & $\mathrm{D}$ & no \\
\hline & & s.m & & $2 \times 0.5$ & 1 & 1 & 0 & & \\
\hline \multirow[t]{2}{*}{5} & 49/M & i.m & $7 \times 6$ & & 4 & 4 & 0 & $\mathrm{D}$ & no \\
\hline & & s.m & & $0.5 \times 0.5$ & 1 & 1 & 0 & & \\
\hline 7 & & s.m & & $2 \times 1.5$ & 1 & 0 & 1 & & \\
\hline \multirow[t]{2}{*}{8} & $57 / \mathrm{M}$ & i.m & $0.5 \times 0.5$ & & 1 & 1 & 0 & $\mathrm{D}$ & no \\
\hline & & s.m & & $3 \times 2.5$ & 2 & 2 & 0 & & \\
\hline \multirow[t]{2}{*}{9} & $67 / \mathrm{M}$ & i.m & $6 \times 4$ & & 2 & 1 & 1 & A & yes \\
\hline & & s.m & & $3 \times 2$ & 2 & 0 & 2 & & \\
\hline \multirow[t]{2}{*}{ Total } & 9 cases & & & & 37 samples & & & 4 diploid & \\
\hline & & & & & & & & 5 aneuploid & 4 heterogeneous \\
\hline
\end{tabular}

D = DNA-diploid; A = DNA-aneuploid; i.m = intra-mucosal component; $\mathrm{s} . \mathrm{m}=$ sub-mucosal component; $*$ Total = total number of samples analysed per case.

reflection of genetic instability, which might be an important mechanism in gastric cancer progression, a low level of aneuploidy and of ploidy heterogeneity should exist in early gastric cancer. To verify this hypothesis we undertook the present study, of which the importance is that multiple tumour samples were studied.

Several findings emerge from this study. Firstly, of our early gastric cancers 9 were entirely diploid and 8 had at least one aneuploid sample. Aneuploidy occurred less frequently in purely intramucosal cancers but this difference did not (because of the limited number of cases) attain statistical significance.

In a previous study of largely superficial gastric carcinomas but with focal infiltration of the muscularis propria we found that both components are usually diploid [15]. In this study, however, a limited number of samples per tumour was analysed, which might be the reason why no aneuploid case were detected. This underscores the importance of extensive tumour sampling for DNA-ploidy analysis.

Secondly, of the aneuploid cases, one was homogeneous and 5 heterogeneous. The heterogeneous cases occurred mostly in the tumours with invasion into the submucosa (4 of 9; 44\%) but rarely in purely intramu- cosal (1 of $8 ; 13 \%)$. Most aneuploid tumours invading the submucosa were heterogeneous, which again underscores the importance of adequate sampling (one sample per two centimetres/maximal length) of the lesions for reliable cytometric assessment.

Our data are consistent with existing progression models of human cancer. In a purely diploid early cancer genetic instability leads to a more aggressive (purportedly more invasive) cell clone, which is reflected in DNA-ploidy heterogeneity. Overgrowth by this clone of the tumour eventually leads to homogeneous aneuploidy $[4,6,17,22]$.

In conclusion, our study, (1) confirms the presence of aneuploid early gastric carcinomas; (2) reveals that these aneuploid tumours are frequently heterogeneous; and (3) suggests that heterogeneity occurs more frequently in tumours invading the submucosa. Adequate sampling of tumours is essential for reliable ploidy assessment.

\section{Acknowledgement}

The authors thank L. Cutuli for technical assistance; S. Burki and J. Maillardet for photography. 


\section{References}

[1] Y. Adachi, M. Mori, M. Haraguchi, K. Sugimachi and M. Tsuneyoshi, Cytophotometric study of nuclear DNA content in scirrhous gastric carcinoma, Pathology 27 (1995), 5-7.

[2] R. Bowman, G. Angelini, C. Cabral, O. Datuin, M. Ota and D. Heustis, Interobserver and intraobserver variation in tumor DNA index as analyzed by static image cytometry: a pilot study, Cell Vision 3 (1996), 291-296.

[3] M.J. Brito, M.I. Filipe, H. Thompson, M.G. Ormerod and J. Titley, DNA ploidy in early gastric carcinoma $(\mathrm{T}+)$ : a flow cytometric study of 100 European cases, Gut 34 (1993), 230-234.

[4] E. Fujimaki, H. Yamashiki, O. Nakano, S. Chiba, H. Tazawa, H. Yamashiki, S. Orii and T. Sugai, DNA ploidy heterogeneity in early and advanced gastric cancers, Cytometry (Communications in Clinical Cytometry) 26 (1996), 131-136.

[5] D.W. Hedley, M.L. Friedlander, I.W. Taylor, C.A. Rugg and E.A. Musgrove, Method for analysis of cellular DNA content of paraffin-embedded pathological material using flow cytometry, J. Histochem. Cytochem. 31 (1983), 1333-1335.

[6] T. Imada, Y. Yamamoto, K. Fukuzawa, Y. Rino, T. Suda, Y. Moriwaki, H. Akiyama, T. Doi, F. Kito and H. Takemura, Flow cytometric analysis of nuclear DNA heterogeneity in gastric cancer, Jpn. J. Clin. Oncol. 7(4) (1997), 221-226.

[7] D. Korenaga, M. Haraguchi, T. Okamura, H. Baba, A. Saito and K. Sugimachi, DNA ploidy and tumor invasion in human gastric cancer, Arch. Surg. 124 (1989), 314-318.

[8] D. Korenaga, T. Okamura, A. Saito, H. Baba and K. Sugimachi, DNA ploidy is closely linked to tumor invasion, lymph node metastasis and prognosis in clinical gastric cancer, Cancer 62 (1988), 309-313.

[9] D. Korenaga, A. Watanabe, H. Anai, Y. Maehara and K. Sugimachi, Development of gastric cancer with special reference to growth and DNA content. Slow and rapid growing types, $E u$ rop. J. of Surg. Oncol. 19 (1993), 463-467.

[10] B. Ljungberg, C. Mehle, R. Stenling and G. Roos, Heterogeneity in renal cell carcinoma and its impact no prognosis - a flow cytometric study, Br. J. of Cancer 74 (1996), 123-127.

[11] S.C. Ming, Classification of gastric carcinoma, in: Gastric Carcinoma, M.I. Filipe and J.R. Jass, eds, Churchill Livingstone, Edinburg, 1986, p. 197.

[12] M. Mori, Y. Adachi, Y. Kakeji, D. Korenaga, K. Sugimachi, M. Motooka and T. Ooiwa, Superficial flat-type early carcinoma of the stomach, Cancer 69 (1992), 306-313.

[13] S. Moriwaki and O. Kimura, Correlation of DNA content between endoscopic biopsy and surgically resected specimens in gastric and colorectal cancer, J. Gastroenterol. 30 (1995), 162168.

[14] T. Murakami, Pathomorphological diagnosis: Definition and gross classification of early gastric cancer, in: Early Gastric Cancer (Gann Monograph on Cancer Research No 11), University of Tokyo Press, Tokyo, Japan, 1972, p. 53.
[15] M.C. Osterheld, R. Laurini and E. Saraga, Early gastric carcinoma with focal advanced cancer: a particular subtype of gastric carcinoma, Hum. Pathol. 29(8) (1998), 815-819.

[16] S.E. Petersen, P. Bichel and M. Lorentzen, Flow-cytometric demonstration of tumour-cell subpopulations with different DNA content in human colo-rectal carcinoma, Europ. J. Cancer 15 (1978), 383-386.

[17] R. Ranaldi, A. Santinelli, G. Fabris, B. Mannello, C. Natoli, N. Tinari and I. Bearzi, A flow cytometric study of early gastric cancer. The detection of high proliferative activity adds important information to the prognosis, Path. Res. Pract. 192 (1996), 1202-1205.

[18] P. Rosenberg, S. Wingren and C. Guerrieri, Flow cytometric DNA-heterogeneity in paraffin-embedded endometrial cancer, Acta Oncol. 36 (1997), 23-26.

[19] J.S. Ross, DNA Ploidy and Cell Cycle Analysis in Pathology, Igaku-Shoin, New York, Tokyo, 1996, p. 2.

[20] M. Rugge, F. Sonego, M. Panozzo, R. Baffa, J. Rubio, F. Farinat, D. Nitti, V. Ninfo and S.-C. Ming, Pathology and ploidy in the prognosis of gastric cancer with no extranodal metastasis, Cancer 73 (1994), 1127-1133.

[21] M. Sakusabe, M. Kodama, Y. Sato, T. Kikuchi and K. Koyama, Clinical significance of DNA ploidy pattern in stage III gastric cancer, World J. Surg. 20 (1996), 27-31.

[22] A. Saito, D. Korenaga, M. Haraguchi, Y. Maehara and K. Sugimachi, Heterogeneity in gastric carcinoma with special reference to DNA content and mitotic activity: histopathologic differenciation, J. Surg. Oncol. 51 (1992), 14-18.

[23] K. Sasaki, T. Hashimoto, K. Kawachino and M. Takahashi, Intratumoral regional differences in DNA ploidy of gastrointestinal carcinomas, Cancer 62 (1988), 2569-2575.

[24] O. Sasaki, K. Soejima and Y. Haraguchi, Intra-tumor DNA ploidy distribution pattern and its relation to histologic type in gastric carcinoma, Path. Res. Pract. 188 (1992), 545-549.

[25] H.F. Stich and H.D. Steele, DNA content of tumor cells. III. Mosaic composition of sarcomas and carcinomas in man, J. Natl. Cancer Inst. 28 (1962), 1207-1218.

[26] N. Tadaoka, T. Aoki, K. Hirai and T. Tsukamoto, A study of DNA heterogeneity on gastric cancer with serosal invasive exposure (Japanese), Gan to Kagaku Ryoho (Japanese Journal of Cancer and Chemotherapy) 21(Suppl. 1) (1994), 21-26.

[27] H. Tomoda and T. Inoue, Flow cytometric analysis of the DNA content in primary and metastatic lesions of colorectal cancer, J. of Surg. Oncol. 59(2) (1995), 101-104.

[28] P. Tosi, L. Leoncini, M. Cintorino, C. Vindigni, C. Minacci, S. Nuti, E. Pinto, A. de Stefano and G. Cevenini, Flow cytometric analysis of DNA ploidy pattern from deparaffinized formalin-fixed gastric tissue, Int. J. Cancer 42 (1988), 868871. 


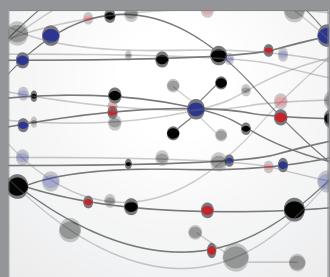

The Scientific World Journal
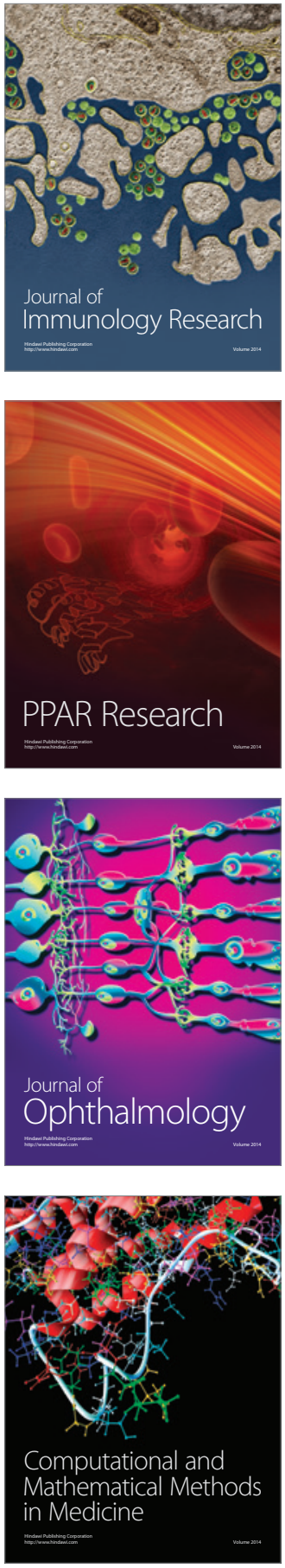

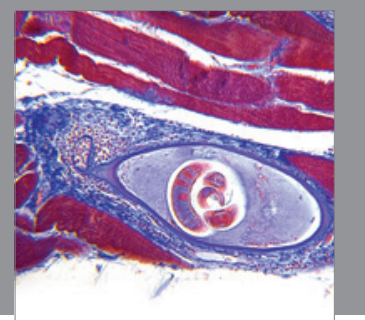

Gastroenterology

Research and Practice
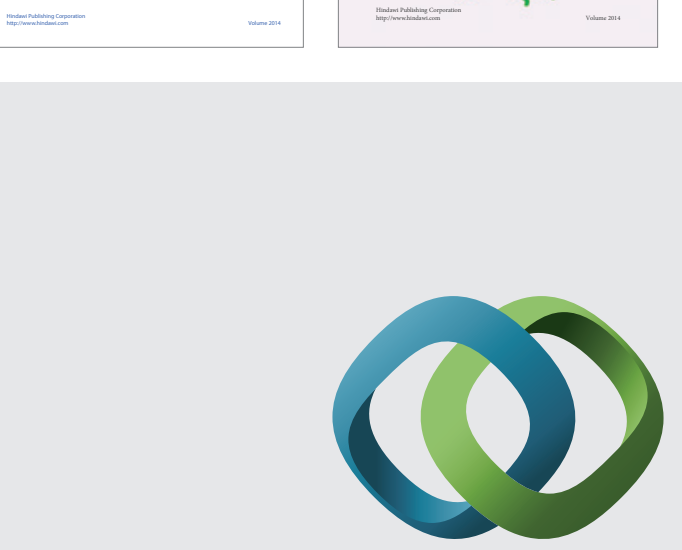

\section{Hindawi}

Submit your manuscripts at

http://www.hindawi.com
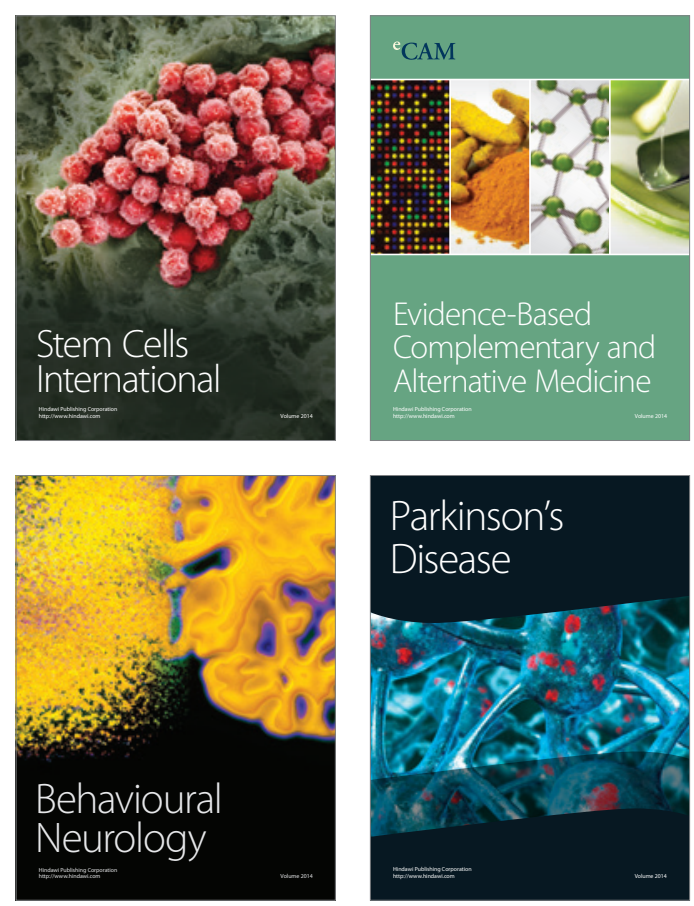

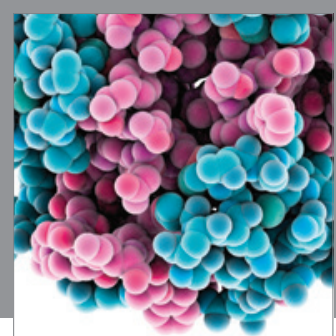

Journal of
Diabetes Research

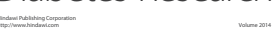

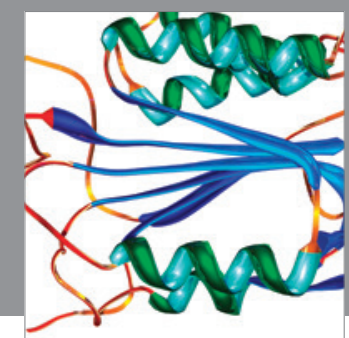

Disease Markers
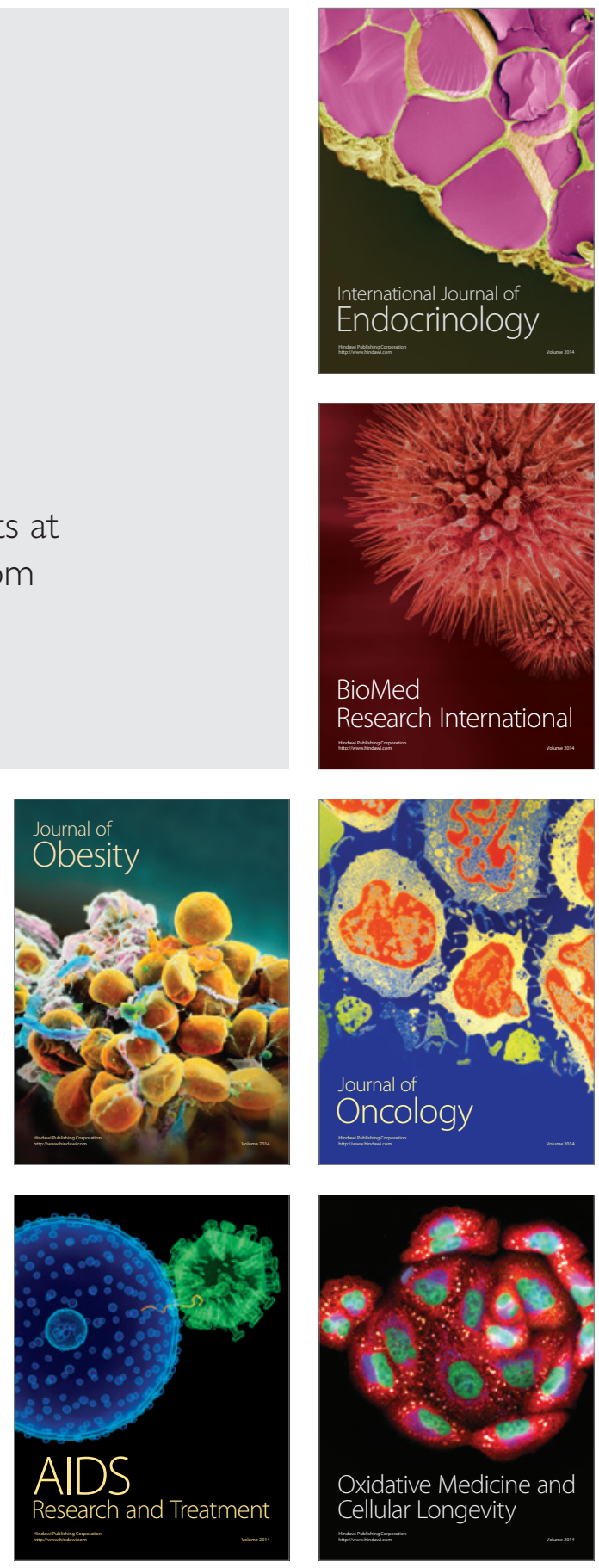